\title{
PERANCANGAN SISTEM INFORMASI PENGGAJIAN PEGAWAI BERBASIS JAVA DI SEKOLAH MENENGAH KEJURUAN NUSANTARA WISATA RESPATI
}

\author{
Meri Chrismes Aruan ${ }^{1}$, Luh Putu Widya Adnyani ${ }^{2}$ \\ Program Studi Informatika, Universitas Indraprasta PGRI \\ meriprincess08aruan@gmail.com
}

\begin{abstract}
Abstrak
Perkembangan dan kemajuan teknologi informasi berbasis IT sangat berkembang pesat dan mempunyai peranan yang sangat penting. Sistem informasi merupakan suatu kebutuhan bagi instansi untuk memanfaatkan informasi sebagai basis administrasi dan pengolahan data. Untuk memenuhi kebutuhan tersebut maka instansi melakukan kegiatan yang berhubungan dengan sistem informasi berbasis komputer sebagai alat bantu untuk meningkatkan kreatifitas para pegawai. Sistem ini dirancang untuk menangani traksaksi perhitungan gaji pengawai dan pembayaran dan dapat menjamin validiitas, otorisasi kelengkapan, klasifikasi penilaian, ketepatan waktu dari setiap traksaksi penggajian. Di Sekolah Menengah Kejurusan Nusantara Wisata Respati masih menggunakan system penggajian yang manual yaitu dengan Microsoft Excel sehingga memungkinkan orang-orang yang tidak berwenang untuk masuk dan melihat data serta dapat mengubahnya yang dampaknya akan mengganggu aktifitas dalam pengolahan data gaji. Untuk itu perlu dibuat Perancangan Sistem Informasi Penggajian Berbasis Java Di Sekolah Menengah Kejurusan Nusantara Wisata Respati.
\end{abstract}

Kata Kunci: Perancangan, Sistem Informasi, Penggajian, Java

\begin{abstract}
The development and progress of IT-based information technology is very rapidly developing and has a very important role. Information systems are a necessity for agencies to utilize information as a basis for data administration and processing. To meet these needs, the agency conducts activities related to computer-based information systems as a tool to increase employee creativity. This system is designed to handle the transaction of escort and payment salary calculations and can guarantee validiity, complete authorization, classification of assessments, timeliness of each payroll transaction. In the Middle School Nusantara Wisata Respati Middle School still uses a manual payroll system, which is Microsoft Excel, so that people who are not authorized to enter and view data and can change the impact will disrupt the activity in processing salary data. For this reason, it is necessary to design a Java-based payroll information system at the Respati Archipelago Tourism Middle School.
\end{abstract}

Keywords: Designing, Information Systems, Payroll, Java

\section{PENDAHULUAN}

Sistem penggajian karyawan merupakan kebutuhan yang sangat diperlukan berguna untuk mengetahui daftar gaji serta tunjangan pada sekolah tersebut. Oleh karena itu, sekolah harus melakukan perencanaan gaji yang tepat dalam arti memiliki keadilan internal, yaitu sesuai dengan tugas, tanggung jawab, dan tingkat usaha yang dilakukan dalam pekerjaan. Gaji adalah sesuatu yang berkaitan dengan uang yang diberikan kepada pegawai atau karyawan [1].

Dalam system penggajian bukan hanya bagaimana suatu instansi dalam mempertimbangkan gaji yang dibayarkan kepada setiap karyawan, tetapi juga mementingkan proses pembayaran gaji yang dilakukan. Dimana Sekolah Menengah Kejuruan Nusantara Wisata Respati masih menggunakan system penggajian dengan menggunakan Microsoft Excel . Dengan adanya keterbatasan Microsoft Excel diantaranya ditemukan redundancy data dan masih ada beberapa proses perhitungan dilakukan dengan cara manual, sehingga membutuhkan tingkat ketelitian tinggi yang akan menimbulkan proses pengolahan gaji menjadi tidak efesien.

Mendasari hal itu, untuk menyelesaikan permasalahan yang ada maka penulis 
melakukan penelitian perancangan system informasi penggajian pegawai berbasis java di sekolah menengah kejuruan Nusantara Wisata Respati untuk memecahkan permasalahan yang dihadapin sekolah tersebut khusnya bendahara sekolah.

\section{A. Perancangan Sistem}

Pada saat hendak membuat system yang akan digunakan pada suatu perusahaan setiap pengembang aplikasi diharuskan membuat sebuah rancangan dari system yang ingin dibuat. Rancangan ini bertujuan untuk memberi gambaran umum dari sistem yang akan berjalan nantinya kepada setiap stakeholder. Perancangan system adalah sekumpulan aktivitas yang menggambarkan secara rinci bagaimana system akan berjalan [2]. Hal itu bertujuan untuk menghasilkan produk perangkat lunak yang sesuai dengan kebutuhan user. Terdapat 3 perancangan system yaitu:

- Perancangan database

- Perancangan proses

- Perancangan interface

Perancangan system adalah sebuah kegiatan merancang dan menentukan cara mengolah system informasi dari hasil analisa system sehingga dapat memenuhi kebutuhan dari pengguna termasuk diantaranya perancangan user interface, data, dan aktivitas proses [3].

\section{B . Sistem Informasi}

Pada Umumnya system informasi merupakan sebuah system yang ada pada sebuah organisasi dimana didalamnya terdapat kombinasi yang terdiri dari kumpulan orang, fasilitas, teknologi bahkan cara kerja atau metode sehingga menciptakan alur sebuah komunikasi serta pemprosesan beragam tipe kejadian internal maupun ekternal yang dapat dijadikan sebagai sebuah dasar dalam penentuan keputusan berdasarkan iinformasi yang terdapat pada system tersebut. Sebuah system tidak dapat berjalan tanpa adanya support atau dukungan operasi dan managemen yang meliputi kombinasi teknologi informasi dan beragam aktivitas manusia yang berperan sebagai pengguna teknologi itu sendiri. Sistem informasi merupakan suatu system didalam suatu organisasi yang mempertemukan kebutuhan pengolahan transaksi harian yang mendukung fungsi organisasi yang bersifat manajerial dalam kegiatan strategi dari suatu organisasi untuk dapat menyediakan kepada pihak luar tertentu dengan laporan-laporan yang diperlukan [4].

\section{Gaji}

Dari sudut pelaksanaan bisnis, gaji dapat dianggap sebagai biaya yang dibutuhkan untuk mendapatkan sumber daya manusia untuk menjalanan operasi dan karenanya disebut biaya gaji.Gaji biasanya digunakan untuk pembayaran kepada pegawai yang digunakan untuk pembayaran kepada pegawai yang diberi tugas-tugas administrasi dan pimpinan [5]. Pada umumnya jumlah gaji ditetapkan secara bulanan atau tahunan. Gaji adalah sebuah bentuk pembayaran atas penyerahan jasa yang dilakukan oleh sebuah perusahaan atau instansi kepada pengawai [6].

\section{Java}

Java dikembangkan oleh perusahaan Sun Microsystem. Java menurut defenisi Sun Microsystem adalah nama untuk sekumpulan teknologi untuk membuat dan menjalankan perangkat lunak pada komputer standalone ataupun pada lingkungan. Java 2 adalah generasi kedua dari java platform [7]. Java merupakan bahasa berorientasi objek untuk pengembangan aplikasi mandiri, aplikasi berbasis internet, aplikasi untuk perangkat cerdas yang dapat berkomunikasi lewat internet/jaringan komunikasi. Melalui teknologi java, dimungkinkan perangkat audio streo dirumah terhubung dengan jaringan computer. Java tidak lagi hanya untuk membuat applet yang memperintah halaman web tapi java telah menjadi bahasa untuk pengembangan aplikasi skala interprise berbasis jaringan besar [8]

Ciri utama dari java:

1. JVW(Java Virtual Machine) 
2. Garbage Collectioon

3. Code Security

\section{METODE PENELITIAN}

Menurut [9] Grounded Research adalah suatu metode penelitian yang mendasarkan diri kepada fakta dan menggunakan analisa perbandingan bertujuan untuk mengadakan generalisasi empiris, menetapkan konsepkonsep, membuktikan teori dan mengembangkan teori di mana pengumpulan data dan analisa data berjalan pada waktu yang bersamaan. Dalam penelitian grounded research metode yang digunakan adalah studi perbandingan yang bertujuan untuk menentukan seberapa besar suatu gejala tersebut berlaku untuk umum. Untuk mendapatkan informasi yang dibutuhkan dari objek yang akan diteliti oleh karena itu dilakukan pengamatan langsung di SMK Nusantara Wisata Respati.

\section{Teknik Observasi}

Teknik pengumpulan data dengan cara melihat, mengerjakan langsung sebagai pelaksanaan kegiatan proses pelayanan dan pemberian laporan kepada bendahara sekolah sehingga penulis mendapatkan ide atau pemikiran yang lebih efesien dan memudahkan bagi pihak-pihak terkait dalam merancangan system penggajian guru dan karyawan di SMK Nusantara Wisata Respati.

2. Studi Pustaka

3. Studi Lapangan

Wawancara dilakukan kepada $\mathrm{Ibu} \mathrm{Ni}$ Wayan Nila Kusuma, S.E.,M.M sebagai bendahara sekolah untuk mengetahui halhal yang terkait pada penggajian dan proses system penghitungan gaji.

Uraian proses penggajian guru dan staf di Sekolah Menengah Kejuruan Nusntara Respati adalah dengan cara proses pendataan pegawai, proses penetapan golongan, proses absensi, proses perhitungan gaji dan proses laporan.

\section{HASIL DAN PEMBAHASAN}

\section{A. Proses Bisnis}

Adapun uraian proses yang terdapat pada pada sistem usulan adalah sebagai berikut:
a. Nama Proses : Login
b. Nama proses : Input Data
c. Nama proses : Hitung Gaji
d. Nama Proses : Laporan

\section{B. Uraian Proses}

Uraian proses pengajian guru dan staf di Sekolah Menengah Kejuruan Nuantara Respati adalah sebagai berikut:

a. Proses Pendataan Pegawai (Guru dan Staf)

b. Proses Penetapan Golongan

c. Proses Absensi

d. Proses Perhitungan Gaji

e. Proses Laporan

\section{Aturan Bisnis}

Aturan bisnis sistem berjalan pada Sekolah Menengah Kejuruan Nusantara Wisata Respati adalah sebagai berikut:
a. Absensi
b. Penggajian
c. Golongan
d. Laporan

D. Kebijakan Pada Sistem
a. Penetapan Gaji
b. Komponen Gaji
c. Pembayaran Gaji
d. Hari dan Jam Kerja
e. Menghitung Gaji

E. Dekomposisi Fungsi

Dekomposisi fungsi merupakan bagan terstruktur tentang pemisahan fungsifungsi yang ada di dalam sistem yang dianalisis.

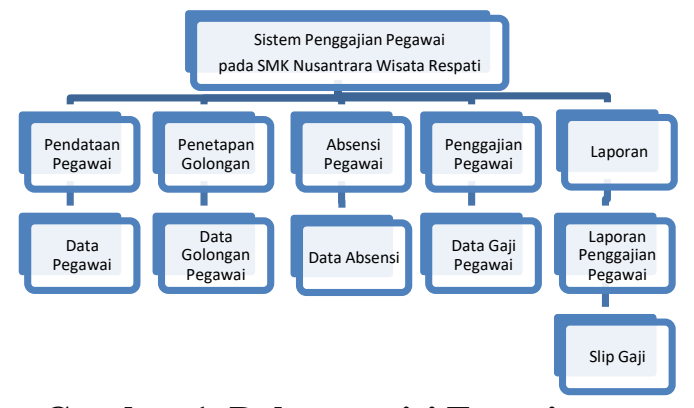

Gambar 1. Dekomposisi Fungsi 


\section{F. Analisa Masukkan (Input), Proses dan Keluaran (Output) \\ Dokumen masukan atau dokumen input adalah segala bentuk masukan yang diperlukan sumber data yang selanjutnya diolah dalam proses sehingga dapat menghasilkan suatu keluaran. Adapun dokumen masukan yang digunakan pada sistem informasi pengolahan gaji guru dan staf pada SMK Nusantara Wisata Respati adalah sebagai berikut:}

\section{Analisa Masukan (Input)}

\begin{tabular}{|c|c|}
\hline a. Nama masukan & ra \\
\hline Fungsi & :Mengetahui data \\
\hline & informasi pengolahan gaji \\
\hline Sumber & Pegawai (guru dan staf) \\
\hline Media & Kertas \\
\hline Periode & Setiap bulan \\
\hline Keterangan & $\begin{array}{l}\text { :Berisi tentang data } \\
\text { pegawai } \quad \text { no_peg }+ \\
\text { nama_peg+ttl+alamat+sta } \\
\text { tus+ jumlah_anak\} }\end{array}$ \\
\hline b.Nama masukan & : Data golongan \\
\hline Fungsi & $\begin{array}{ll}\text { :Memberikan } & \text { data } \\
\text { golongan pegawai }\end{array}$ \\
\hline Sumber & : Pegawai (guru dan staf) \\
\hline Media & : File \\
\hline Periode & Setiap bulan \\
\hline Keterangan & $\begin{array}{l}\text { :Berisi tentang data } \\
\text { golongan } \\
\text { pegawai\{no_peg+nama_ } \\
\text { peg+golongan+ } \\
\text { gaji_pokok\} }\end{array}$ \\
\hline c. Nama masukan & Data absensi pegawai \\
\hline Fungsi & $\begin{array}{l}\text { :Mengetahui absensi } \\
\text { kehadiran, lembur dan } \\
\text { keterlambatan pegawai }\end{array}$ \\
\hline Sumber & : Pegawai (guru dan staf) \\
\hline Media & : Kertas \\
\hline Periode & :Setiap bulan \\
\hline Keterangan & $\begin{array}{l}\text { :Berisi tentang data } \\
\text { absensipegawai\{no_peg+ } \\
\text { tgl+jam_masuk+jam_kete } \\
\text { rlambatan+jam_lembur\} }\end{array}$ \\
\hline d.Nama masukan & :Data gaji \\
\hline Fungsi & $\begin{array}{l}\text { :Untuk mengetahui data } \\
\text { gaji pegawai }\end{array}$ \\
\hline Sumber & :Keuangan \\
\hline Media & :File \\
\hline
\end{tabular}

Periode

Keterangan

\author{
:Setiap bulan \\ :Berisi tentang data gaji \\ pegawai\{no_peg+nama_ \\ peg+golongan+gaji_poko \\ $\mathrm{k}+$ lembur+potongan+tran \\ sport+total_gaji\}
}

\section{Analisa Proses}

Proses yang terjadi saat kegiatan sistem informasi pengolahan gaji pegawai pada SMK Nusantara Wisata Respati yaitu:

a. Proses Pendataan Pegawai

Proses pendataan pegawai dilakukan oleh bagian Tata Usaha, data pegawai berasal dari formulir yang telah diisi oleh pegawai.

b. Penetapan Golongan

Proses penetapan golongan pegawai ditetapkan oleh bagian Keuangan, data pegawai berasal dari bagian Tata Usaha.

c. Proses Absensi Pegawai

Proses absensi pegawai terjadi pada saat pegawai telah datang ke sekolah sebelum memulai kegiatannya.

d. Proses Perhitungan Gaji

Proses hitung gaji pegawai terjadi setiap akhir bulan setelah bagian Tata Usaha menyerakan laporan rekapan absensi pegawai kepada bagian keuangan. Proses hitung gaji pegawai dilakukan oleh bagian keuangan.

e. Proses Laporan

Proses laporan dilakukan setiap akhir bulan setelah bagian Keungan selesai membuat rekapan gaji pegawai. Bagian Keuangan menyerahkan laporan gaji pegawai kepada Kepala Sekolah untuk mendapatkan persetujuan atau tanda tangan dari Kepala Sekolah.

\section{Analisa Keluaran (Output)}

a. Nama keluaran Fungsi

Sumber

Distribusi

Media
:Laporan absensi :Untuk membuat laporan absensi pegawai setiap bulan :Pegawai :Tata Usaha :File 
Periode

Keterangan

b. Nama keluaran

Fungsi

Sumber

Distribusi

Media

Periode

Keterangan
:Setiap bulan

:Berisi data absensi

pegawai\{no_peg

+nama_peg+total

_kehadiran+total

jam_lembur+ja

m_keterlambatan

\}

:Data pegawai

:Membrikan

informasi data

pegawai

:Pegawai

:Tata Usaha dan

Keuangan

:File

:Setiap bulan

:Berisi tentang

data

pegawai\{no_peg

+nama_peg+ttl+a

lamat+status+ jumlah_anak\}

c. Nama keluaran $\quad: \quad$ Slip gaji

Fungsi

Sumber

Distribusi

Media

Periode

Keterangan

f. Nama keluaran
Fungsi

Sumber

Distribusi

Media

Periode

Keterngan
Membuat

laporan

daftar gaji

setiap

bulannya

sebagai arsip

di bagian

Keuangan.

Keuangan

Pegawai

Kertas

Setiap bulan

Berisi daftar

gaji dari

seluruh

pegawai

yang menerima

gaji

\section{G. Diagram Alir Data (DAD) Konteks, Nol dan Rinci}

\section{Diagram Konteks Sistem Berjalan}

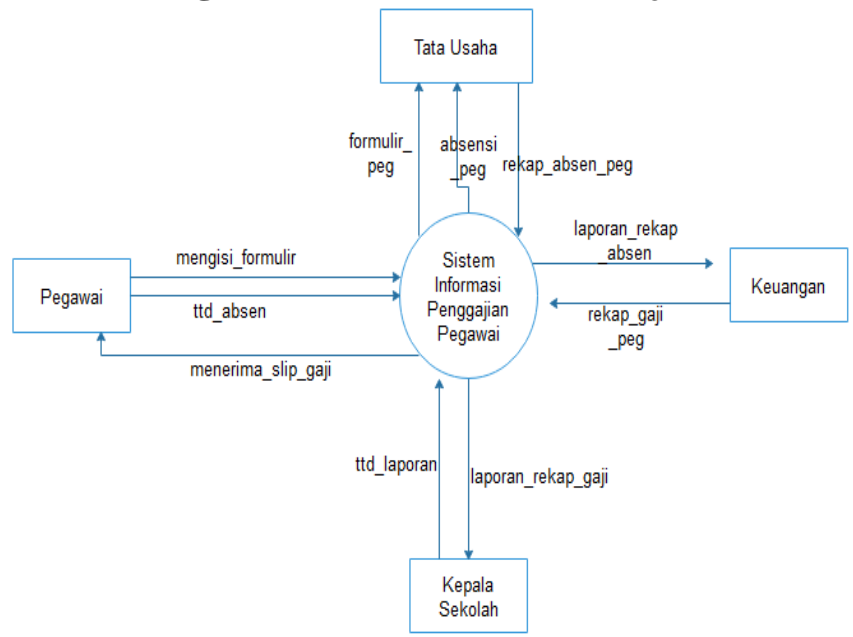

Gambar 2. Diagram Konteks Sistem Berjalan

- Diagram Nol Sistem Berjalan 


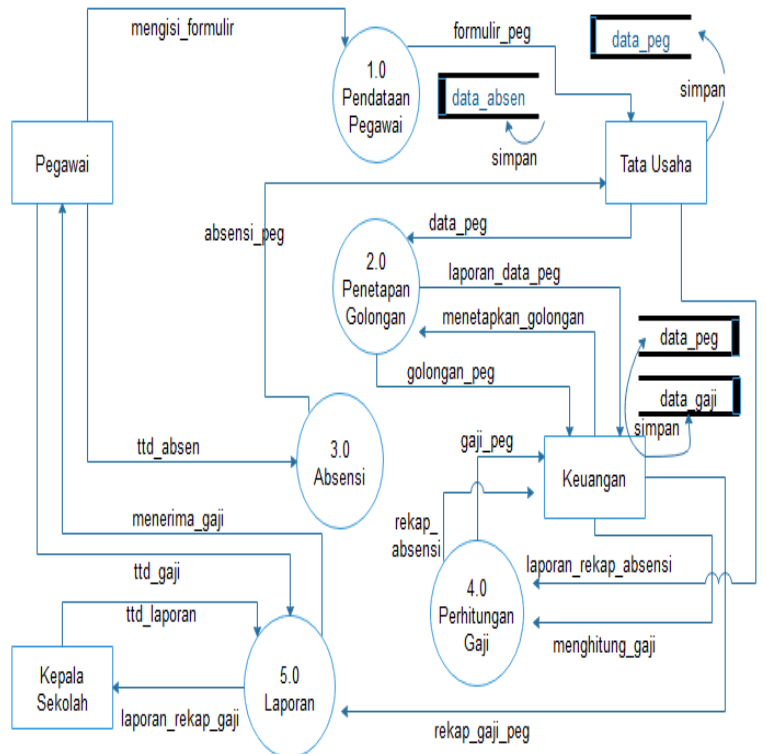

Gambar 3. Diagram Nol Sistem Berjalan

- Diagram Rinci Sistem Berjalan

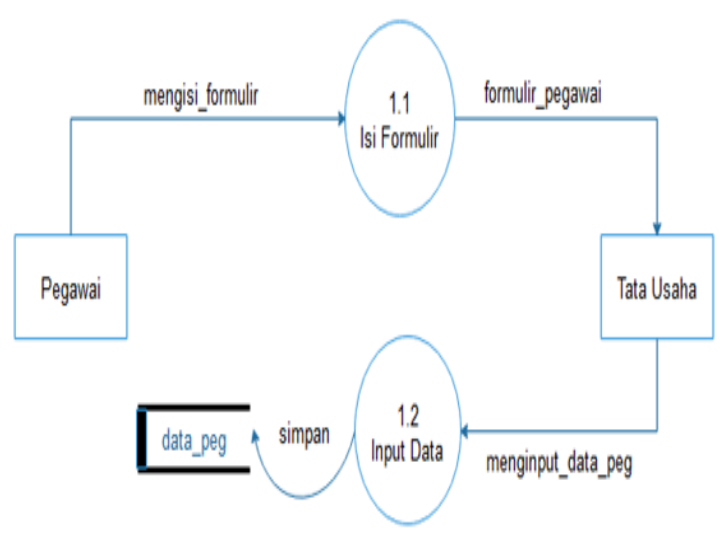

Gambar 4. Diagram Rinci Level 1.0 Sistem Berjalan

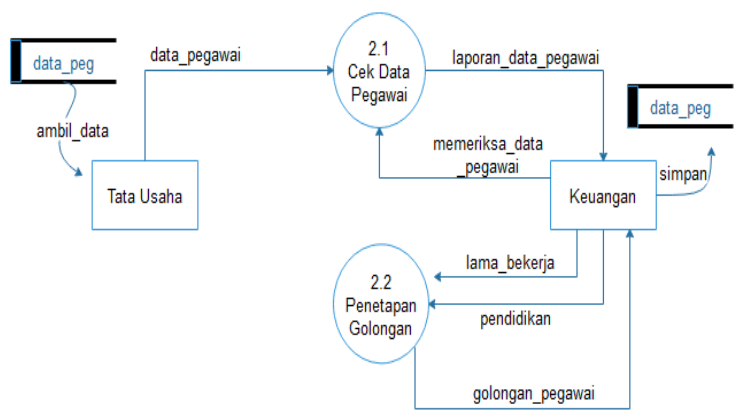

Gambar 5. Diagram Rinci Level 2.0 Sistem Berjalan

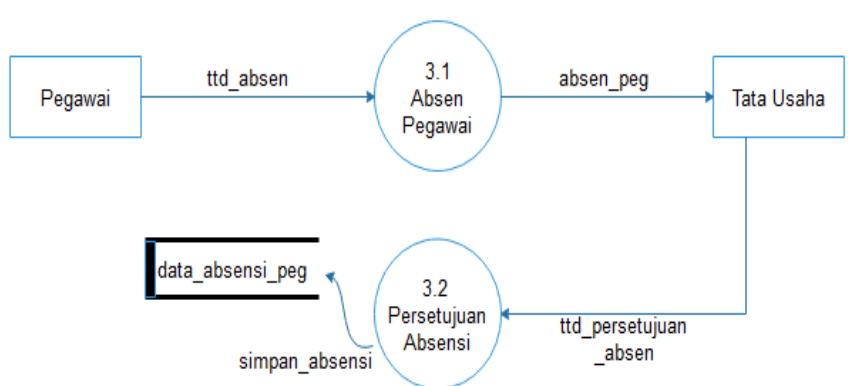

Gambar 6. Diagram Rinci Level 3.0 Sistem Berjalan

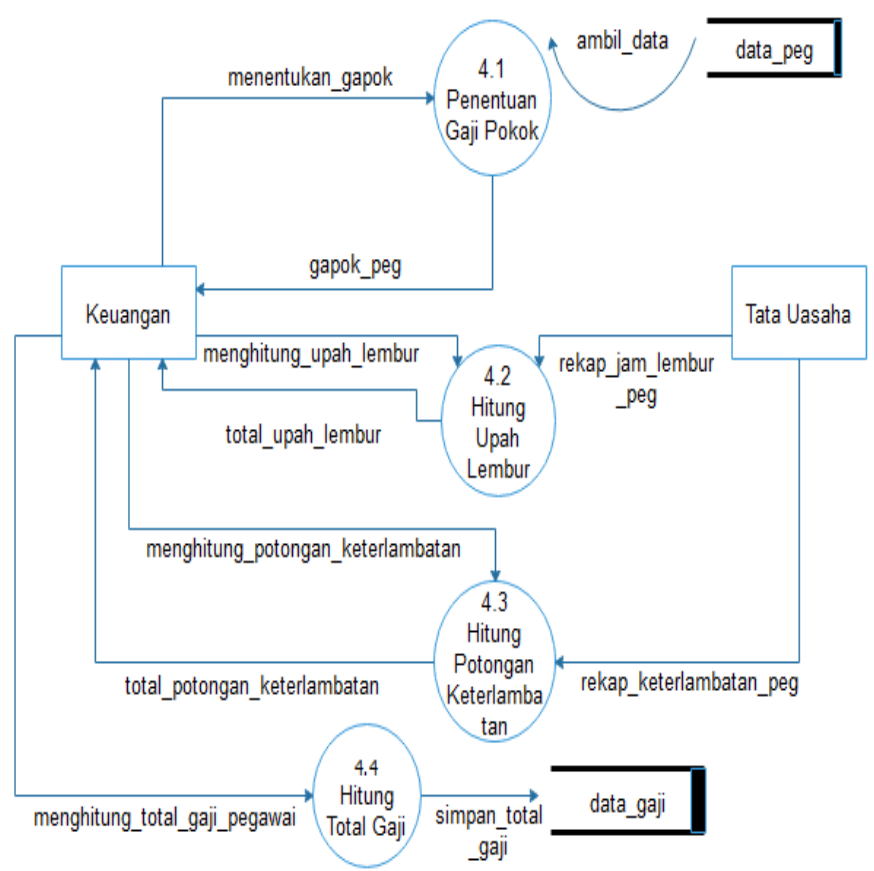

Gambar 7. Diagram Rinci Level 4.0 Sistem Berjalan 


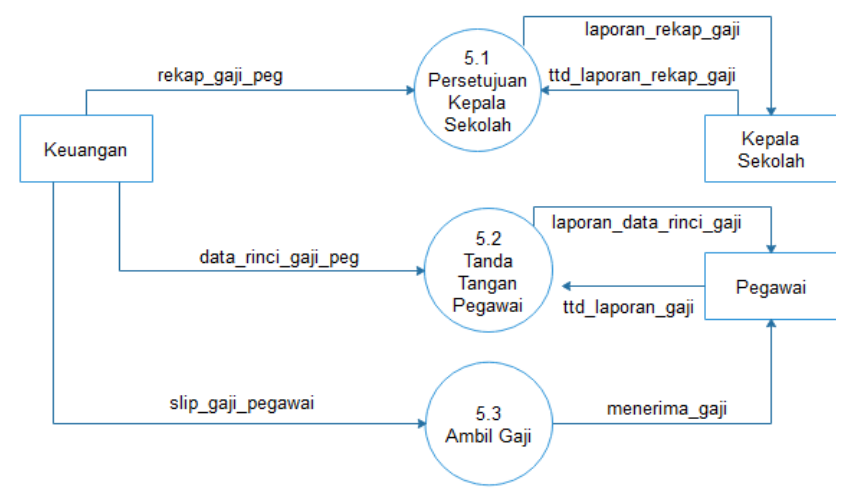

Gambar 8. Diagram Rinci Level 5.0 Sistem Berjalan

\section{H. Analisa Basis Data}

\section{Entity Relationship Diagram (ERD)}

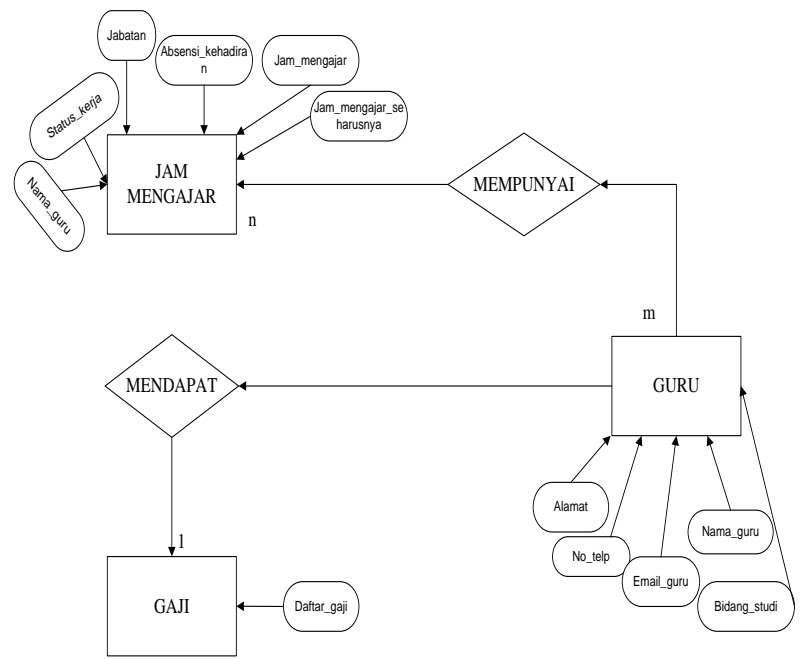

Gambar: 9 ERD

\section{Spesifikasi File Basis Data}

a. Nama file

Media

Organisasi

Primary key

Panjang record

umlah record
: Data guru

: Hardisk

:Index Sequential

: nmgr

: 100 byte

: $50 \times 1 \times 26 \times 24=$ 31200 record
Struktur data :

Tabel 1. Data Guru

\begin{tabular}{|c|c|c|c|c|}
\hline $\begin{array}{c}\mathrm{N} \\
\mathrm{o}\end{array}$ & Field & Type & Value & Keterangan \\
\hline 1 & nmgr & Varchar & 50 & Nama guru \\
\hline 2 & almt & Varchar & 100 & Alamat \\
\hline 3 & Notlp & Int & 20 & No telepon \\
\hline 4 & Emgr & Varchar & 50 & Email guru \\
\hline 5 & Bidstd & Varchar & 50 & Bidang studi \\
\hline
\end{tabular}

b.Nama file

Media

Organisasi

Primary key

Panjang record

Jumlah record

Struktur data
: Data jam mengajar

: Hardisk

: Index Sequential

: stskrj

: 100 byte

: $50 \times 1 \times 26 \times 24=$ 31200 record
Tabel 2. Data Jam mengajar

\begin{tabular}{|c|c|c|c|c|}
\hline No & Field & Type & Value & Keterangan \\
\hline 1 & Nmgr & Varchar & 50 & Nama guru \\
\hline 2 & Stskrj & Varchar & 20 & Status kerja \\
\hline 3 & Jbtn & Varchar & 20 & Jabatan \\
\hline 4 & Absnsi & Varchar & 10 & Absensi \\
\hline 5 & Jmmngjr & Varchar & 5 & Jam mengajar \\
\hline 5 & Jmmngjrshrs & Varchar & 5 & Jam mengajar \\
& & & & seharusnya \\
\hline
\end{tabular}

c. Nama file

Media

Organisasi

Primary key

Panjang record

Gaji

: Hardisk

Jumlah record

: Index Sequential

: dftrgj

: 50 byte

: $50 \times 1 \times 26 \times 24=$

31200 record

Struktur data $\quad$ : Tabel 3 Gaji

\begin{tabular}{|c|c|c|c|c|}
\hline No & Field & Type & Value & Keterangan \\
\hline 1 & P_tahun & Varchar & 10 & Periode tahun \\
\hline 2 & P_bulan & Varchar & 10 & Periode bulan \\
\hline
\end{tabular}




\begin{tabular}{|c|c|c|c|c|}
\hline 3 & Nik & Varchar & 12 & NIK \\
\hline 4 & Nama & Varchar & 50 & Nama \\
\hline 5 & Jabatan & Varchar & 12 & Honor jabatan \\
\hline 6 & Intensif & Varchar & 12 & Uang intensif \\
\hline 7 & $\begin{array}{r}\text { Honor_m } \\
\text { engajar }\end{array}$ & Varchar & 12 & Honor mengajar \\
\hline 8 & Transport & Varchar & 12 & Uang transport \\
\hline 9 & Piket & Varchar & 12 & Honor piket \\
\hline 10 & Potongan & Varchar & 12 & Jumlah potongan \\
\hline 11 & Bon_gaji & Varchar & 12 & Jumlah bon gaji \\
\hline 12 & Kehadira & Varchar & 12 & Jumlah kehadiran \\
\hline 13 & Total & Varchar & 12 & Total gaji bersih \\
\hline
\end{tabular}

b.Lembar Kerja Tampilan (LKT) T2 Halaman Admin

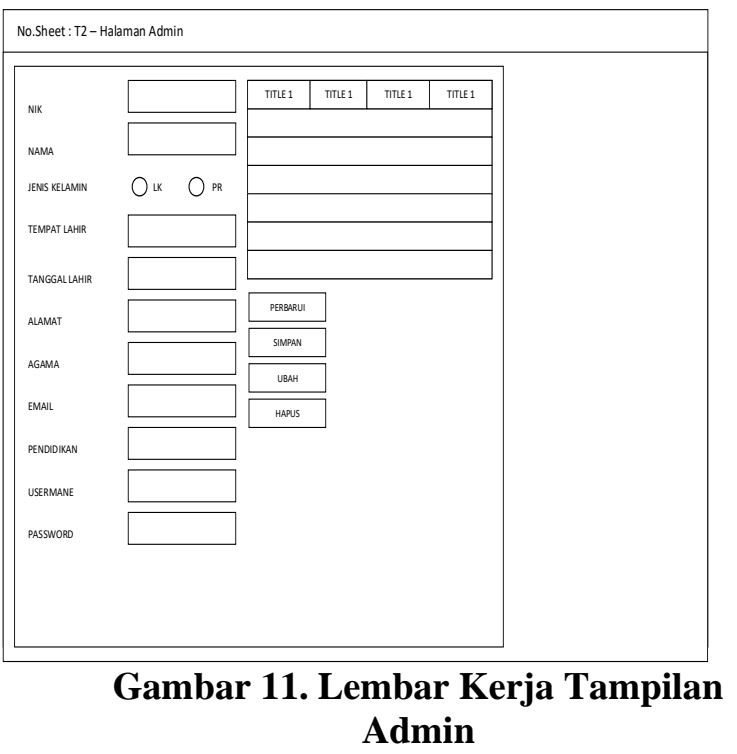

\section{J. Rancangan Layar, Rancangan Form Masukkan dan Rancangan Form Keluaran}

1.Rancangan Layar a.Lembar Kerja Tampilan (LKT) T1 Login

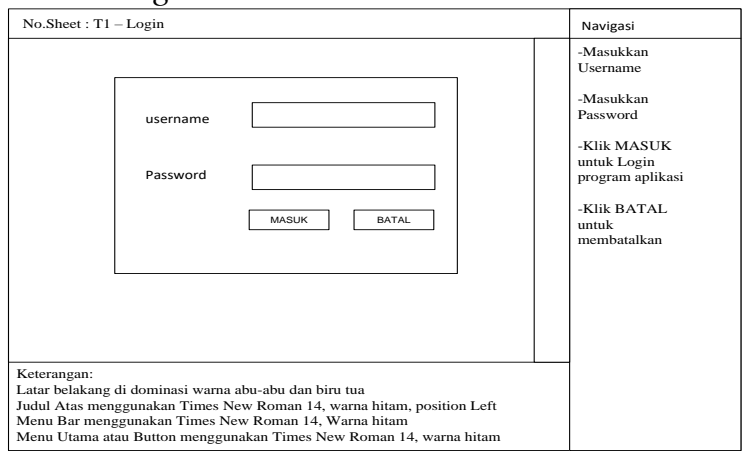

Gambar 10. Lembar Kerja Tampilan Login

c.Lembar Keja Tampilan (LKT) T3 Data Pegawai

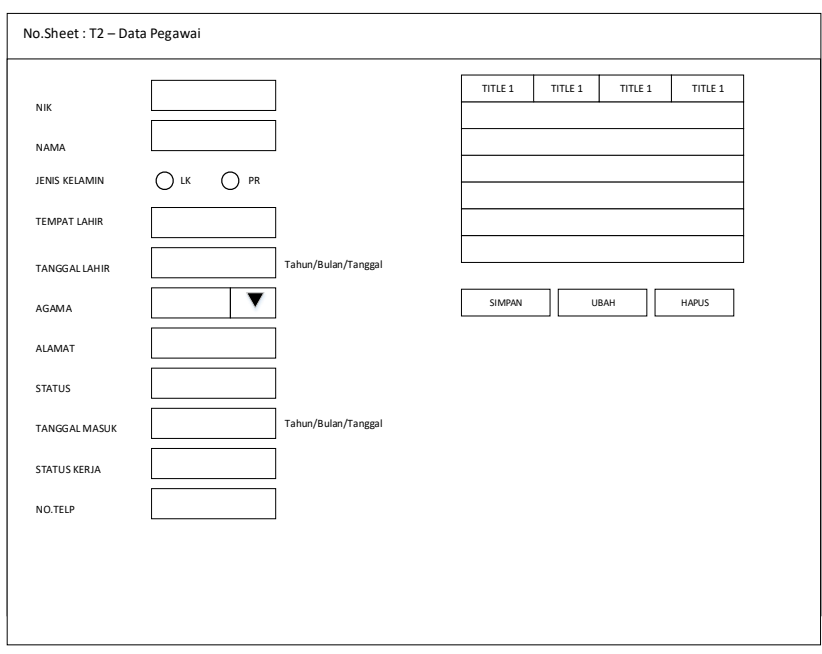

Gambar 12. Lembar Kerja Tampilan Data Pegawai 
d.Lembar Kerja Tampilan (LKT) T4 Data Penggajian

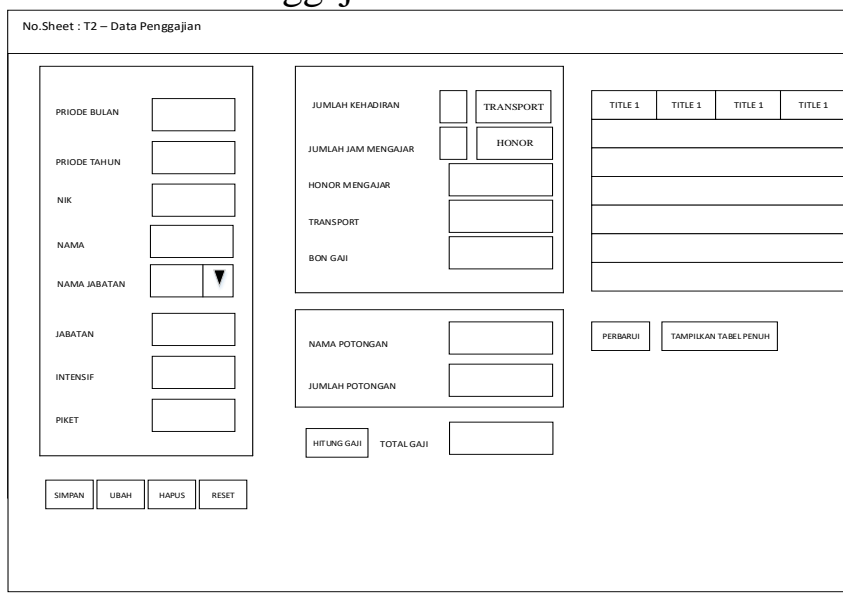

Gambar 13. Lembar Kerja Tampilan Data Penggajan

\section{Rancangan Form Masukkan dan Rancangan Keluaran}

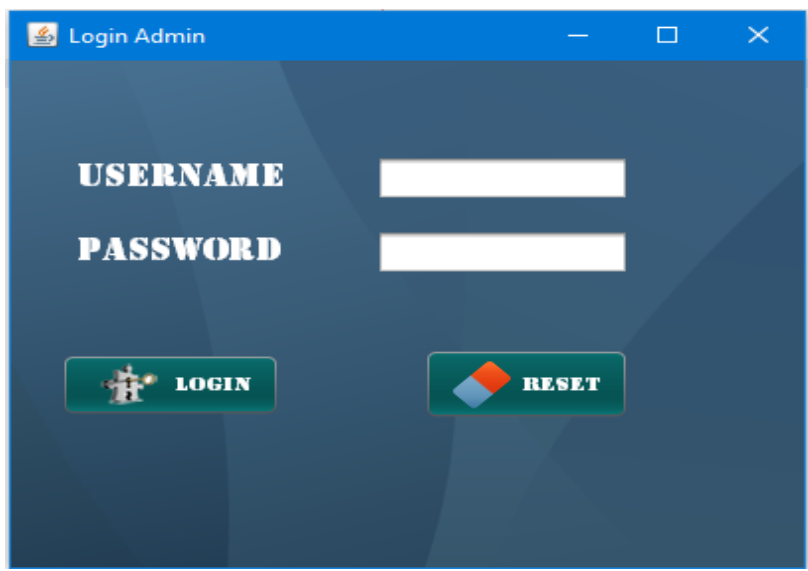

Gambar 14. Tampilan Login

Tampilan login untuk masuk ke sistem informasi pengolahan gaji pegawai pada SMK Nusantara Wisata Respati

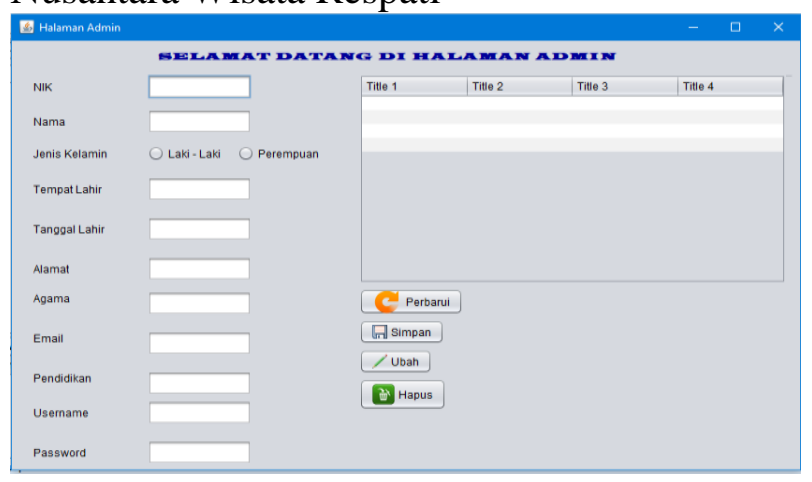

Gambar 15. Tampilan Awal Admin
Tampilan awal admin di dalam sistem informasi pengolahan gaji pegawai pada SMK Nusantara Wisata Respati.

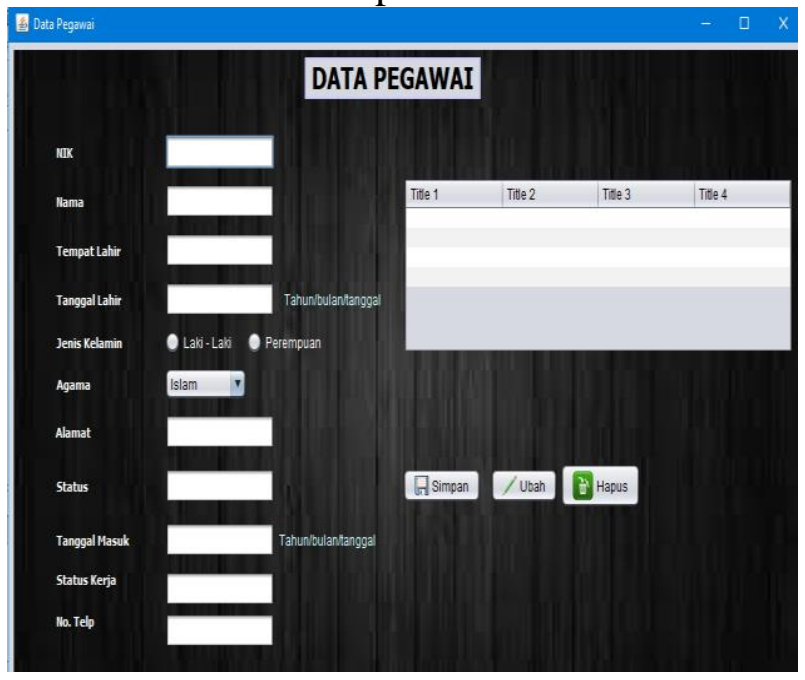

Gambar 16. Tampilan Biodata Pengawai

Tampilan biodata pegawai dimana admin dapat memasukan data, dan mengubah data.

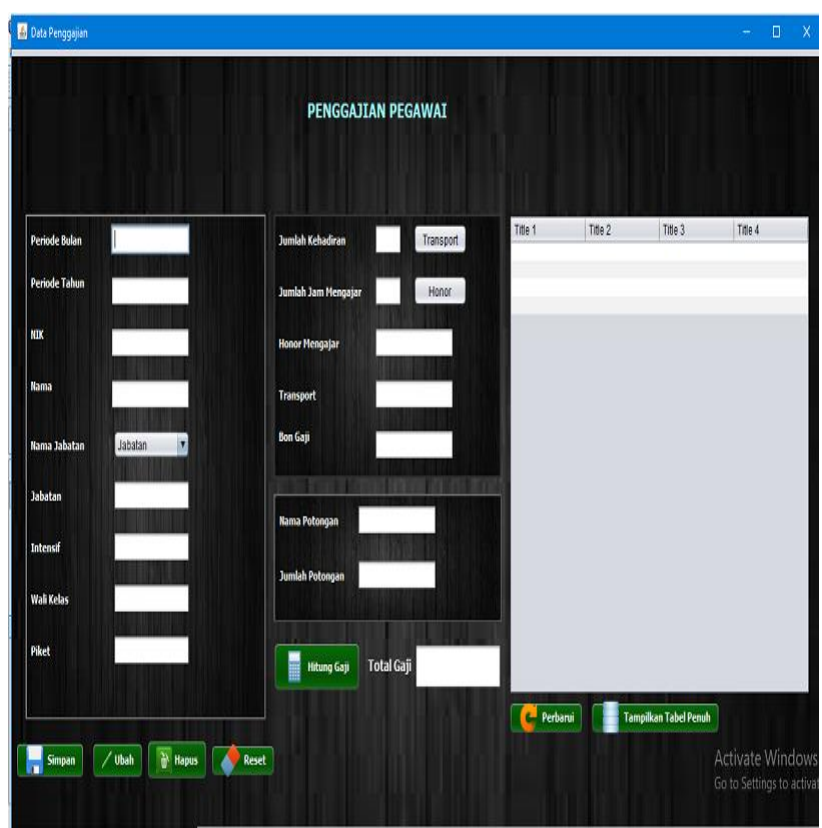

Gambar 17. Tampilan Admin Penggajian

Tampilan data gaji pegawai dimana admin dapat memasukan data gaji berdasarkan nik, nama karyawan dan mengedit jika ada kesalahan. 


\section{SIMPULAN DAN SARAN}

\section{Simpulan}

Dari pembahasan dan analisa perancangan aplikasi penggajian pegawai (guru dan staf) di SMK Nusantara Wisata Respati maka dapat disimpulkan sebagai berikut :

1. Tujuan perancangan aplikasi penggajian guru dan staf adalah untuk memberikan informasi tentang transaksi penggajian sekolah.

2. Menu-menu yang menyusun perancangan aplikasi ini ialah menu file, master data, transaksi dan laporan.

3. Software yang digunakan :

a.Netbeans IDE 7.2 digunakan untuk merancang semua tampilan aplikasi.

b.Apache dan MySQL digunakan untuk mengolah database.

4. Sistem yang diusulkan ini menyimpan semua data yang berhubungan dengan semua transaksi ke dalam database. Sehingga mempermudah admin dalam memperoleh data yang telah lama disimpan untuk diakses kembali dengan mudah dan efisien.

5. Untuk laporan keluaran diambil dari hasil masukan data dan transaksi yang admin telah simpan terlebih dahulu dalam database melaui form input data. Dari data tersebut maka laporan dapat dihasilkan yang nantinya dapat dicetak dan diserahkan kepada pihak yayasan.

\section{Saran}

Berikut beberapa saran yang dicantumkan untuk memaksimalkan kinerja dari aplikasi penggajian guru dan staf di SMK Nusantara Wisata Respati :

1. Agar memudahkan pihak sekolah dan admin dalam melakukan pengitungan gaji dan laporan maka diharapkan dalam prakteknya menggunakan sistem yang diusulkan.

2. Agar admin juga bisa menjalankan dan membuat pengembangan perancangan aplikasi penggajian guru dan staf maka diharapkan juga harus dapat memahami program aplikasi NetBeans sesuai dengan sistem yang diusulkan ini.

3. Agar berkas-berkas yang berkaitan dengan transaksi pembayaran gaji tidak hilang atau rusak maka datadata yang berkaitan harus disimpan dalam suatu database yang bisa dilakukan dengan penggunaan sistem yang diusulkan ini.

\section{DAFTAR PUSTAKA}

[1] Samsudin, Salidi. Manajemen Sumber Daya Manusia. Bandung : Pustaka Setia. 2015.

[2] Satzinger,J.W.,Jackson,R.B, dan Burd, S.D. System Analysis and Design $\ln A$ Changing World USA: Cengage Learning. 2012.

[3] O'Brien dan Marakas. Management Information System. Ninth Edition. New York: McGraw-Hill/Irwin. 2009.

[4] Sutabri Tata. Sistem Informasi Manajemen. Yogyakarta: Andi. 2009.

[5] Soemarso. Akuntansi Suatu Pengantar. Edisi Evisi. PT. Salemba Empat: Jakarta. 2014.

[6] Mardiasmo. Perpajakan. Edisi Revisi. Yogyakarta: Andi. 2011.

[7] Rosa. Rekayasa Perangkat Lunak. Jakarta: PT. Elex Media Komputindo. 2015.

[8] Bambang. Esensi-esensi Bahasa Pemrograman Java. Yogyakarta: Andi. 2012.

[9] Nazir. Metode Penelitian. Bogor: Ghalia Indonesia. 2014. 